\title{
Spatial dependence of diurnal temperature range trends on precipitation from 1950 to 2004
}

\author{
Liming Zhou • Aiguo Dai · Yongjiu Dai · Russell S. Vose • \\ Cheng-Zhi Zou $\cdot$ Yuhong Tian $\cdot$ Haishan Chen
}

Published online: 4 April 2008

(c) Springer-Verlag 2008

\section{Erratum to: Clim Dyn \\ DOI 10.1007/s00382-008-0387-5}

During the production process the color table of Fig. 3 was displaced. The correct figure is given below.

The online version of the original article can be found under doi:10.1007/s00382-008-0387-5.

\section{Zhou ( $₫)$}

School of Earth and Atmospheric Sciences,

Georgia Institute of Technology,

311 Ferst Drive, Atlanta, GA 30332, USA

e-mail: 1z35@mail.gatech.edu; lmzhou@eas.gatech.edu

\section{A. Dai}

National Center for Atmospheric Research,

P.O. 3000, Boulder, CO 80307, USA

\section{Y. Dai}

School of Geography, Beijing Normal University,

100875 Beijing, China

\section{R. S. Vose}

Climate Analysis Branch, National Climatic Data Center,

Asheville, NC 28801, USA

\section{C.-Z. Zou}

Office of Research and Applications,

NOAA/NESDIS, Camp Springs, MD 20746, USA

Y. Tian

IMSG at NOAA/NESDIS,

Camp Springs, MD 20746, USA

\section{H. Chen}

Jiangsu Key Laboratory of Meteorological Disaster,

Nanjing University of Information Science and Technology,

210044 Nanjing, China
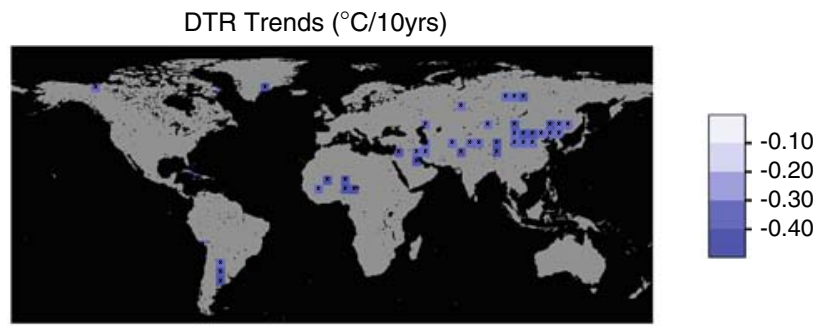

Climatic Regions: 11
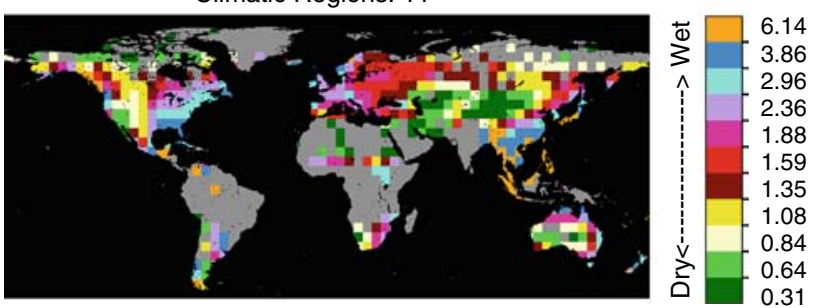

Fig. 3 Spatial pattern of observed annual DTR trend as shown in Fig. 2 but only for those grid boxes whose DTR trends are less than $0.20^{\circ} \mathrm{C} / 10$ years (upper panel). An example of eleven climatic regions defined based on the climatological annual precipitation amount from 1950 to 2004 (lower panel) 